\title{
Tanzania's Language of Instruction Policy Dilemma: Is there a Solution?
}

\author{
Nyankomo W. Marwa \\ University of Stellenbosch Business School, South Africa \\ Email: nyankomo.marwa@gmail.com
}

Doi:10.5901/mjss.2014.v5n23p1262

\begin{abstract}
After independence, Tanzania adopted a unique language of instruction model (Lol) in which Elementary school education is taught in Swahili and Secondary and Postsecondary schools are taught in English. This model has provoked contentious public policy debates because of its inherent inefficiency, especially when students are transitioning from Swahili to English as a medium of instruction. The difficulties arising as student transitions between two languages affect their academic performance negatively. The long term effect is creation of a structural dent in producing locally trained graduates who are less competitive in the job market. This paper explores the evolution of Tanzania's language of instruction model and outlines problems it creates from the learners and society perspectives. Also, it identifies potential policy constraints and proposes a feasible policy compromise.
\end{abstract}

Keywords: Policy Dilemma, Language of Education Model, Tanzania, Globalization

\section{Introduction}

"... Secondary level the data reveals that teachers and students fail to learn effectively through the sole medium of English. Kiswahili is used in class for teachers to express themselves effectively and for students to understand their teachers. Kiswahili is the de facto medium of instruction in many class-rooms. Those teachers who were seen using only English in class were often found to be misleading their students. Code-switching is not the solution for a bilingual education system. It is therefore recommended that Kiswahili become the medium of education at secondary school" (MEC, 1998; xiii)

The language of Instruction (Lol) in Tanzania has continuously been a controversial public policy debate. The existing model involves Swahili as a language of instruction for primary education and English as the language of instruction for secondary and postsecondary education. The challenges arise when students are transitioning from primary to secondary education. There is a general consensus that the current model is ineffective; however, there is no agreement on whether to choose Swahili as the major Lol at all educational levels or English as the universal language of instruction (BrockUtne, 2002). The paper aims to explore the language of instruction policy dilemma, its negative effects on Tanzania's social economic development and propose a possible solution. The insights obtained by exploring the historical context and the evolution of Tanzania's language of instruction model will help to outline problems created by the current model both from students' and economic perspective. Existing policy constraints will be identified and feasible policy compromise will be proposed. The key questions to be answered are: Why was the current model adopted? Why does a policy dilemma exist despite the consensus on its ineffectiveness? Is there a solution?

The existing literatures have focused on the impact of the Lol model on academic performance (Brock-Utne, 2010). There are a limited number of studies that specifically concentrates on the policy dilemma surrounding the current Lol model. Therefore, this paper aims to address the problem of policy dilemma and shed some light on the possible solutions using political economy analysis. The conclusion derived based on this work provides some insights on the ongoing debate on Lol and suggests possible alternatives in addressing the problem.

The rest of the paper is organized as follows: section 2 presents the background of a Swahili language and the evolution of the current language of instruction model in Tanzania; section 3 presents a theoretical approach; section 4 explains the social-economics implications of the current model; section 5 presents policy constraints and a compromise solution. The paper ends with a conclusion in section 6.1

\section{Background of a Swahili Language and Historical Context of the Current Lol Model}

During pre-independence, most of the African countries typically faced several challenges including how to mobilize and 
organize local citizens, with diverse ethnic and language background into a unified group of freedom fighters. A common language as a medium of communication was imperative for effective coordination of the liberation struggle from colonialism. Tanzania, in particular, had more than 120 ethnic groups speaking different languages (EALE, 2011). To achieve a common goal for the independence struggle, a common language was needed as a unification factor for the diverse ethnic groups prevailing in the country. The cultural and ethnic heterogeneity within the country prompted the preindependence leaders, including Mwalimu Julius Kamabagare Nyerere, the first president of Tanzania, to recognize the importance of a common language and leveraged from using Swahili as a unification tool. By then, the language was mainly spoken in the coastal zone and urban centers.

The strategy of using Swahili as a unified language turned out to be very successful. The language became widely spread and was recognized as one of the official languages of Tanzania after independence (English was the second official language). Since then, it has been one of the important tools for human capital development through training and coping with ethnically-based and social conflict contrary to many similar African countries. During post- independence, the government replaced English by Swahili as a medium of instruction for an elementary education. Such a decision resulted into an educational language model in which a Swahili is used as medium of instruction for all public primary schools and English is used as language of instruction for secondary and post-secondary institutions country-wide. Figure 1 below provides a simplified version of Tanzania's language of instruction model.

Figure 1: A simplified current Lol Model in Tanzania is graphically presented below

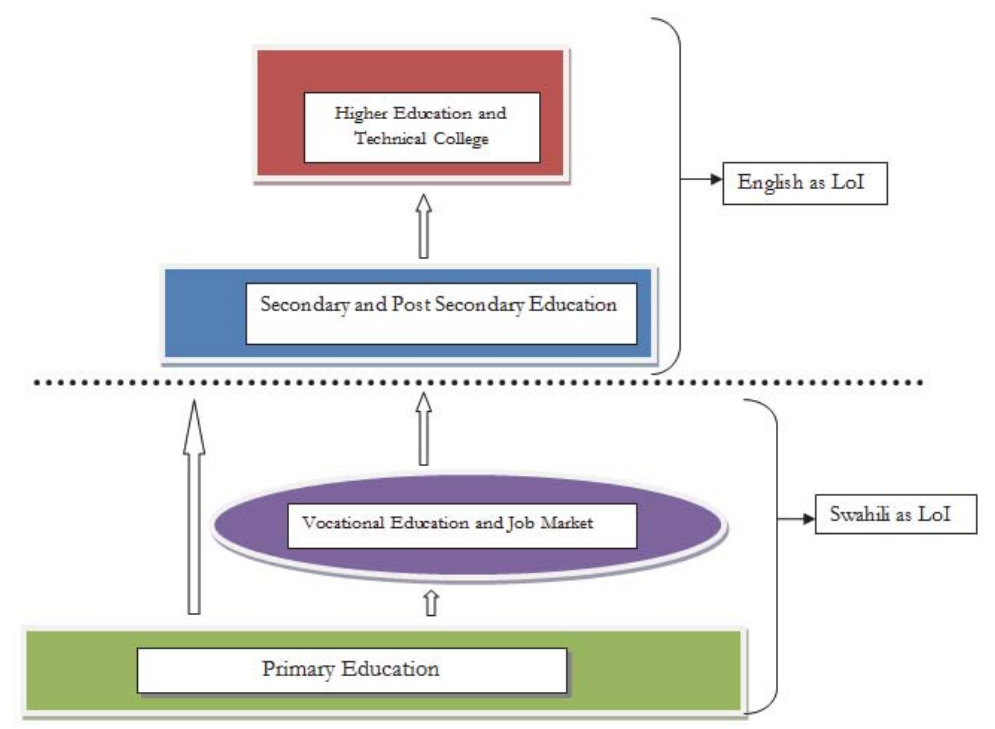

Source: Author 's Own Sketch

Currently, Tanzania is one of the few countries in Africa that has a home grown language (Swahili) that almost the whole population (about 95\%) speaks and understands. For many Tanzanians, Swahili is the second language; however the number of people who use it as the first language is rapidly growing especially in mixed ethnic families in urban centers. The language is used in Parliament, in the various Ministries, in the lower judicial courts and in all of the primary schools. Plans existed to have Kiswahili as the language of instruction in secondary school and the universities (Brock-Utne, 2002). A detailed historical narration of the language policy of Tanzanian education is well illustrated in previous literature (Brock-Utne, 1993; 2000:2001a; 2001b).

In brief, English was used as a Lol in pre-independence Tanzania. After independence, the introduction of Swahili as the medium of instruction in primary schools was thought to be only part of a larger plan to implement the use of Swahili as the medium of instruction throughout the educational system. Despite the attempt and design of a cultural policy 1962 (updated 1997), which decided to change the Lol from English to Swahili at secondary schools and at University level, the actual implementation of policy has been inactive. Some analysts claim that academician at the University level decided on the language of instruction, bypassing the Ministry of Education, the politicians and the Government. The justification for the decision includes the concern about the current and projected global trends and the fact that English is rapidly becoming the ICT language globally (MEC,1997:73). 


\section{Theoretical Approach}

The political economy theories are used to analyze the causes and possible solutions of the policy dilemma. This study focuses on institutional approach to understand the role of institutions on: path dependency, political influence and power, collective action and coordination problem, culture and identity. Path dependence theory describes a situation in which initial conditions establish a trajectory, making changes or reversal increasingly difficult. The key features of path dependence are: the influence of the initial conditions; increasing returns, self-reinforcement, and positive feedback, large set up costs, and coordination effects (Pierson, 2004). The coordination problem arises in a situation where there are two or more possible Nash equilibrium of which one is superior to another. Thus, the payoff will be the highest when players coordinate their strategies (Varian, 2003). In the context of Lol policy dilemma, it is predicted that if the players collectively coordinate their action they may solve the dilemma and end up with a Pareto superior policy option.

Based on the theoretical prediction, once the institutions develop, they exhibit self-reinforcing incremental changes which lead to path dependence (Pierson, 2004). Williamson (1937) argues that culture provides the key to path dependence, which is a term used to describe the powerful influence of the past on the present and future. The current knowledge of any generation takes place within the context of the perceptions derived from collective learning which is an incremental process filtered by the culture of a society and impliedly determines the perceived pay-off. Also, political influence and power plays important role in influencing institutional changes and sustainability. Power is defined as a capacity that an individual or a group has to influence the behavior of other individuals or groups so that the influenced group may acts in accordance with wishes of the group with power (Robbins and Judge, 2007). Thus, at least, from theoretical prediction I expect the group(s) with political power or land economic power will use it to their best interest either to change or sustain the status quo.

\section{Analysis and Discussion}

This section, starts by demonstrating the socio-economic challenges of the current language of instruction model. Later, institutions, culture and identity, path dependency, political influence and power contexts are used to analyze the different forces which play the significant roles in reinforcing or weakening the policy dilemma. Last but not least potential policy constraints are identified and possible compromise is proposed for the Lol dilemma.

\subsection{Lol Model, Quality Education, Educational Performance and Policy Dilemma}

The key linkage between the Lol and socio-economic effect is through quality education and educational performance. Quality education is defined as the correspondence between the goals or expectations of society and the changes that take place in among the learners, the education system and the society at large (Qorro, 2008). Expectations of society, according to Mmari (2000), are "expressed in terms of educational goals that can broadly be classified into three categories, namely: (i) learning goals, which focus on equipping the learners with knowledge, skills, values and attitudes as defined in a given curriculum; (ii) system goals, which relate to measurable inputs and outputs that keep the system working; and (iii) educational goals, which are based on the dominant ideas within the society. Since every society has its ideas, it follows that the goals of education between societies will naturally differ; and to that extent the quality of education will also vary". The heterogeneity of educational goals across societies warrants closely linking the quality of education to the goals and objectives of the education in that particular society.

In the context of Tanzania, studies by Andersen (1975) and Mvungi (1982) contends that proficiency in the language of instruction is an important factor in educational performance. "The corollary of this is that lack of proficiency in the language of instruction, in our case English, results in poor performance in subjects taught in English" (Qorro, 2008). Elsewhere, studies by Cummins $(1979,1981)$ and Krashen $(1985)$ urgues that poor performance in the language of instruction results in poor performance not only in other subjects, but also in overall poor performance in the second or foreign language. These findings have been confirmed by studies in Tanzania by Roy-Campbell and (Qorro,1987) and (Qorro,1999). In other words, when students have a firm grasp of their specialized subjects, that understanding gives them a firm ground on which to build the foundation for learning a second or foreign language, in this case English. However, this firm grasp/understanding, which is central to the quality of education, can only be achieved when teachers and students understand the language of instruction. In the secondary schools and higher education's classrooms in Tanzania, the language of instruction (English) is not well understood by the majority of teachers and most students (Qorro, 2008).

Consequently, a persistent problem in grasping the language of instruction among teachers and students has led 
to a cyclical language deficiency and educational performance problem across the entire education system. As a consequence majority of the teachers struggles with language trying to teach the students in the language they do not understand well, on graduating if such particular student happens to join the teaching profession, then the problem goes on and may result into a structural dent in the entire educational system. This implies that the language problems of the graduates and new professionals are passed onto the subsequent generation of pupils who will inevitably turn out with poorer English compared to that of the earlier generations. It is through this process of recycling poor English language into the school system that the level of English language proficiency has kept on falling over the years (Qorro, 2008).

The cyclical phenomenon explained above has both short term and long term problems. In the short term it affects the student performance and learning ability and in the long term it creates a systemic problem of a structural inefficiency which results into relatively less competent locally trained graduates. The local graduates are competitively disadvantaged in the terms of mastery and competence of the English language which is widely used as a global business language and language of science and technology. With increased regionalization and free movement of capital and labor across east African community, the regional job market has been dominated by the graduates from Kenya, Uganda and Nigeria. While there may be other factors apart from English mastery, the mere fact that you cannot communicate effectively in English places you in a tough spot.

Several commissioned studies on the language situation, have come to a consensus that, the model need to be changed; what is not clear is which direction the change should be? There are those who argue that quality of education and educational performance will be improved if both students and teachers use the language which they understand well i.e. Swahili in the case of Tanzania (Qorro, 2008). While there are group which argue that, English should be taught from elementary education and concerted effort should be in place to ensure that those who teach have the relevant qualities and qualifications to teach. The advocates of English as the sole medium of instruction emphasize that, it will enable Tanzanians to mesh easily with the international business and science and technology community, which is dominated by English as a medium of communication (Broc-Uktne, 2007; The Africa, 2003; Guardian, 1999; Daily News 1996 cited by Qorro 2008).

The politician, academician and general public are divided on which language to adopt. This results to a policy dilemma on which language of education should be implemented. Choosing Swahili as the major language of instruction from elementary school through higher education is pedagogically most feasible option because all students and teachers understand the language well. This will enhance the learning experience and educational performance. Also it has strong cultural appeal due to national identity preservation. The downside of this option is the short term operational costs of retraining and translating the academics materials from English to Swahili, the cost of isolating the country from the rest of the global scientific and business community which is dominated by English and the fear to lose the existing position(which is already not good enough) in global competition. Adopting English as a Lol has strong global integration appeal, but it raises the concern about losing the national identity and cultural values. Thus, exclusively switching to any of the two languages involves tough choices which may results in significant political, social and economic costs.

\subsection{Institutions, Culture, National Identity and Path Dependency}

The historical antecedents behind evolution and success of Swahili language have created strong cultural values and attachment to the language itself as home grown identity. There is an elaborate discourse about 'values' for linguistic resources, in which Swahili and English are two bipolar options. Based on value perspective, the historical debates on language in Tanzania can be recast and re-read as debates inspired by clashes of value against the backdrop of group interests. While Swahili have cultural and identity dimension associated with it, English have economic and class values associated with it. Realizing economic dimension is claimed to be crucial in re-routing the debate over language of instruction in Tanzania (Neke et al, 2003). Nevertheless, there is still strong ideological controversy between two contending camps that is English versus Swahili, nationalism dogma, anti foreign, anti colonial, and anti imperialism rhetoric were (and still are) used as a convenient excuse in the argument for the replacement of English with Kiswahili in post-primary education (Mohamed, 2005). The key argument here is that, once the language was adopted it became part and parcel of the cultural values. It received recognition as a national identity, national symbol and created self reinforcing mechanism embodied within the institutional and norms fabrics.

According to Williamson (1981), culture provides the key to path dependence which is a term used to describe the powerful influence of the past on the present and future. The current learning of any generation takes place within the context of the perceptions derived from collective learning. Learning then is an incremental process filtered by the culture of a society which determines the perceived pay-off. After a long history of struggle for independence there have been mixed perception about use of English vs Swahili and the society has developed different perceived pay off. There are 
those who perceive English as an elite language and language for economic opportunities and there are others who perceive it as neo-colonialism tool.

However, it is important to re-visit Williamson's argument which emphasis that there is no guarantee that the cumulative past experience of a society will necessarily fit them to solve new problems. Societies that get "stuck" embody belief systems and institutions that fail to confront and solve new problems of societal complexity." In line with the Williamson's argument, the current Lol model needs to be revised to fit in with the new socio-economic problems facing the country. With the increasing rate of globalization and competition in labor market and service industry, urgent action needs to be taken.

\subsection{Political Influence and Power}

In the political spheres, the Lol is a sensitive topic which has a potential of either breaking political capital or making it depending on the way it is framed and the general perception from the broader constituency. Since there is a divide among citizens, politicians and academics, many politicians tend to shy away from provoking such emotional debates. Unless there is a concerted push from the general public, politicians have no incentive to invest their resources and time on this agenda.

Central to the debate of politics and power, are those groups which support the use of Swahili as the language of instruction in secondary school and the University against those who prefers English as major language of instruction from elementary school to the University level. Unfortunately the second group had the most strength because they are backed by powerful donors like British Council, US-AID and the World Bank. They argue that, "English is the language of development, of modernization, of science and technology and the language of the global village". Parents among the elites would frequently send their children to neighbouring countries where the language of instruction is English. Also some private, so-called "international" primary schools, had started popping up in the country for children of well off to do parents. These schools would use English as language of instruction from grade one in primary school (Brock-Utne, 2002).

\subsection{Regionalization and Globalization}

The past three decades have witnessed the fastest growth of regional economic organizations in sub Saharan Africa, of which Tanzania is a member state. These includes: SADC, ECOWAS, East African Community, and African Union. Apart from regionalization, the rate of globalization and inter-continental trade agreement with Europe, Asia and North America is on the rise. Most of these agreements are made in English as the de-facto language of communication. Thus for the citizens from the member states to effectively participate and take full advantage of the system, the mastery of the medium of communication, which is English in this case, is of significant importance. In sum, as the regionalization and globalization become more dominant the pay off resulting from using English language a universal language of instruction increases. At the same time the cost of using Swahili as a universal language of instruction through post primary education increases at least from the economics side of the argument.

\subsection{Collective Action and Coordination Problem}

The current Lol model has differential impact on the different groups across the country. The group which bears most of the burden is the youth and young graduates who find it difficult to compete in the job market with the neighboring countries' candidates, especially from Kenya and Uganda. Unfortunately these groups do not have political influence and they are scattered in different parts of the country with literately no organized group to represent them. Lack of coordination among this group escalates their frustration from reaching political and media attention.

The next is the group of parents who strives to spend their hardly earned income to send their children abroad especially Kenya and Uganda or in locally available English medium schools with a hope that by the time they graduate they will have a level playing field in the job market. Unfortunately this group is also very diverse and their members are not organized to exert any significant pressure on the policy change. The next group is politicians and administrative elites; this group is more concerned with their political career and job security and has no incentive to involve in such a controversial policy which may cost their political capital. Also most of them have enough financial resources to send their children to elite schools and abroad. Once their children receive the best education available they come back and take advantage of both human capital and social capital to get the top positions within the private or government agencies. In sum at the end of the day the net losers are poor families and middle class. This group lack both economic power and 
political influence which leaves the Lol agenda politically dormant.

\section{Policy Constraints and a Compromise Solution}

Tanzania's ability to address the controversial Language of Instruction Policy is heavily constrained by factors mentioned above i.e culture, national identity and path dependency; political influence, power and interest group; coordination problem; regionalization and globalization. The solution for the policy dilemma implies making a tough choice among the two alternatives languages by taking into account the four issues raised. In this section I discuss each of the issue and propose a possible solution in getting a compromise for the effective language of instruction policy.

\subsection{Culture, National Identity and Path Dependency}

The importance of culture cannot be over emphasised, however as the quality of education and level of competence of locally trained graduates become a serious concern, it is likely that the perceived values of the cultural and national identity argument, will become weaker and weaker (if it not is already weak enough). As part of the solution the private sector are providing English as medium of instruction, starting from elementary school through high school. Unfortunately, these schools are very expensive for average citizen to afford and it is very competitive to get admission because of high demand. The existence of the parallel education system have reinforced the divide between the rich and poor .For well off families, their children get better education and are more likely to secure better jobs compared to those coming from public schools. Also as globalization expands and the influx of foreign workers in the local market increases the cost of maintaining cultural values and National identity will be questioned. All this put together, it is more likely such systematic effect will provide a negative feedback loop instead of positive feedback loop and reverse the trajectory for path dependence. Thus, even though cultural and national identity concerns have been among the key policy constraints, its validity may be questionable given the changing global and local circumstances.

\subsection{Political influence and Power}

Since the argument of the national identity and perceived pay off is likely to get weaker, what is required from political side is to identify a dedicated political leader who is willing to take the agenda serious and create avenue for political will to change the policy for good. This will involve advocacy and awareness campaign among the constituency, politician, academics and other stakeholders. The issue which remain to be solved is which language to adopt? However the experience shows that countries like Ghana, Botswana, Kenya, Uganda, Nigeria which were once colonized by Britain and decided to adopt English as universal language of education, they are relatively doing well. While I acknowledge the importance of using Swahili as medium of instruction, the stakes of using English in the highly integrated global market are obvious.

\subsection{Collective Action and Coordination Problem}

As most of the affected groups by the current Lol are youth, lower and middle income families, which form more than $80 \%$ of the total population, there is a need for coordinating their effort to improve the current situation. It may sound like impossible for a vastly populated country like Tanzania to coordinate about 40+ million people to support the agenda, however, if there is effective use of the mass media and lobbying groups, the policy change will be possible. Thus once there is political will and right framing of the agenda it is likely to generate strong public support for desired policy change.

Politicians, parents, future students, and the society at large are likely to be better off if they solve the coordination problem and change the current Lol model. If successful politician will be credited for innovative policy solutions, academics will receive well prepared students linguistically and focus on the technical aspect of teaching. Student will take advantage of the coherence of the learning environment and become more competitive in the labour market. Parents will benefit by getting the superior service to their children in return for their tax dollar.

\section{Conclusion}

Cultural identity, long term economic prospect through quality of human capital produced is two competing forces central to the Lol dilemma in Tanzania. To solve the dilemma, there is a need to make a tough choice between the two. However, theoretical and empirical studies have showed that there a strong link between human capital, productivity and 
economic development. Thus the answer to whether there is a solution to policy dilemma is yes, but it depends on the location of the pivotal weight on the preference of the majority and political authority between the two options. As the circumstances changes, the economic options are more likely to dominate. Such dominance can be predicted as a two stages process. In the first stage, as globalization and regionalization increases, local graduates become less competitive, internal pressure and discontents with a status quo will accumulates.

In the second stage, the interactions between the discontents of the status quo and weakened citizens' welfare may lead to weakening the cultural and national identity constraints. This may be further amplified by the increasing exposure of the local labour market to regional and global labour supply. More specifically inability of the local work force to compete both locally and globally due inadequate technical and language skills may escalate the problem. Thus, an increasing rate of globalization and the use of English language a global medium of instruction will increase the propensity of the majority to be inclined towards the use of English language as a de-facto choice for instruction including primary schools. The big challenge is how to find the effective coordination mechanism to get a consensus among politician, academics, parents and other interest group. A possible solution to this is the use of media advocacy and use of strong lobbying groups to ensure that, the agenda is popularised and receive necessary attention to warrant changes.

In this paper I have focused almost entirely on the obstacles and hurdles that face the use of the current language of instruction model. This focus is not because I wish to highlight only the negative, but rather because I believe these hurdles are real and must be addressed, and that to be addressed they must be well understood. Indeed, much more research and discussion is required on these topics if the educational system is to respond to the challenges it is increasingly facing.

\section{References}

Andersen, R. (1975). The Language Factor', occasional paper No. 1, Department of Foreign Languages and Linguistics, UDSM

Brock-Utne, B.(2002). The most recent developments concerning the debate on language of instruction in Tanzania. Presented to the NETREED conference from the 7 th to the 9th of January 2002.

Brock-Utne, B. (1993). Language of instruction in African schools - a socio cultural perspective. Nordisk Pedagogik. No. 4 pp. 225-247.

Brock-Utne,B. (2000). Whose Education for All? The Recolonization of the African Mind. New York/London: Falmer Press.

Brock-Utne,Birgit, (2001a). Education for All - in whose language? Oxford Review of Education. Vol.27.No.1.pp.115-134.

Brock-Utne,B. (2001b). The use of African languages - a question of learning and a question of democracy. Le Revue Gabonaise des Sciences du Langage. (in press)

Bull, A.F. (2005). Looking back thirty Years and Forward: The Story of the East African Swahili Committee. Journal of the Institute of Kiswahili Research, 2005, pp.232-234

Chacha, D.M. (2006) . Kiswahili and The African States: The Legacy of Mwalimu Julius Kambarage Nyerere. Journal of the Institute of Kiswahili Research, Vol. 69, 2006

Cummins, J.(1979). Cognitive/Academic Language Proficiency, Linguistic Interdependence, the Optimal Age Question and Some Other Matters. Working Papers on Bilingualism, 19, 197-205.

Cummins, J.(1981). The Role of Primary Language Development in Promoting Educational Success for Language Minority Students' in Schooling and Language Minority Students: A Theoretical Framework, 3-49.

EALE.(2011). Tanzania Ethnic Groups. East Africa Living Encyclopedia, University of Pennsylvania

Krashen, S. (1985), The Input Hypothesis: Issues and Implications, New York: Longman.

MEC (Ministery of Education and Culture) (1997). Sera ya Utamaduni

Mvungi, M. (1974). Language policy in Tanzania with emphasis on implementation. University of Dar es Salaam, Dar es Salaam, Tanzania. Unpublished MA dissertation.

Mohamed, H I. (2005). Critical Issues on the Language of Instruction (LOI) in Secondary and Higher Education in Tanzania. In Uongozi Journal of Management Development Dynamics, Vol. 17 (1): Pp. 32-51.

Neke, S.M; H I. Mohamed \& G.N. Shumbusho. (2003). Explaining Social-cultural and economic inequality in Tanzania: an analysis of some of the narratives from the Medium of Instruction debate. In Uongozi Journal of Management Development, Vol. 15 (1): Pp 22-43.

Pierson, P. (2004). Politics in Time: History, Institutions and Social Analysis. Princeton: Princeton University Press

Qorro, M. A. S. (1999). A Qualitative Study on the Teaching and Learning of Writing in Tanzania Secondary Schools in Relation to Writing Requirements of Tertiary Education', unpublished Ph.D. Thesis, University of Dar es Salaam

Qorro, M .(2008). Does Language of Instruction Affect Quality of Education? Available online http://www.hakielimu.org/hakielimu/ documents/document101does_lang_instruc_fct_qual_edu_en.pdf

Robbins,S.P and Judge,T.A.(2007). Organizational Behavior. (12th Edition) 12th edition. Prarson/Prrnticr Hall

Roy-Campbell and Qorro, M. (1987). A Survey of the Reading Competence in English among Secondary School Students in Tanzania', a Research Report funded by IDRC

Williamson, O.E (1981). The Economics of Organizations: The Transaction Cost Approach." American Journal of Sociology 87 (3): $548-577$

Varian , H.(2003).Intermediate Microeconomics. Fifth Edition. W. W. Norton \& Company 